\title{
ESTIMASI STOK KARBON PADA VEGETASI HUTAN RAWA GAMBUT DI KAWASAN LINDUNG IUPHHK-HTI PT. MUARA SUNGAI LANDAK KABUPATEN MEMPAWAH PROVINSI KALIMANTAN BARAT
}

\author{
(Estimation of Vegetation Carbon Stock on Peatland Forest in Protected Area of IUPHHK-HTI \\ PT. Muara Sungai Landak Mempawah District West Kalimantan Province)
}

\author{
Mohammad Taufiq Hidayat, Dwi Aatiani, Iswan Dewantara \\ Fakultas Kehutanan Universitas Tanjungpura Pontianak. Jl. Daya Nasional Pontianak 78124 \\ e-mail: jagiletis@gmail.com
}

\begin{abstract}
Carbon stock is carbon stored both on the ground and land surface as plant biomass, dead plants (necromas), and in soil as soil organic matters. Change in carbon form becomes the basis for calculating emissions, where most of the carbon $(C)$ elements that broken down into the air are usually bound to $\mathrm{O}_{2}$ and become $\mathrm{CO}_{2}$. Deforestation and degradation are the main threats on forest conservation in Indonesia. Deforestation and forest degradation that occur in Indonesia has led to the development of issues as a significant contributor to carbon emissions. The purpose of this study is to estimate carbon stocks in protected area at PT. Muara Sungai Landak Mempawah Regency, West Kalimantan Province. This study used non-destructive sampling. This method, was done by measuring the diameter of the tree and then using an allometric equation that is suitable for estimating biomass. The making of sample plots in this study is stratified on land cover condition and systematic sampling. The results show that carbon stock for the entire area/cover of the protected area of PT. Muara Sungai Landak is 25.970.08 tons. The highest carbon was in old shrubland cover with total of 15.425 .15 tons, followed by young thicket 10.356.46 tons $C$. The smallest stock was in open peat land of 188.46 tons $C$. The calculation of vegetation in this study show the old shrub cover is 128.8 tons/ha.
\end{abstract}

Keywords: Allometric Equation, Carbon Stock, Protected Area, Stratified Sampling.

\section{PENDAHULUAN}

Peranan hutan sangat disorot setelah terjadinya peningkatan suhu di permukaan bumi. Indonesia yang memiliki hutan terluas ketiga di dunia dituntut untuk memberikan kontribusi dengan cara meningkatkan produktivitas hutan dalam penyerapan karbon, Keseluruhan karbon hutan, sekitar $50 \%$ diantaranya tersimpan dalam vegetasi hutan. Sebagai konsekuensi, jika terjadi kerusakan hutan, kebakaran, pembalakan dan sebagainya akan menambah jumlah karbon di atmosfer.

Penyebab utama deforestasi adalah adanya konversi kawasan hutan secara permanen untuk pertanian, perkebunan, pemukiman, dan keperluan lain. Penggunaan kawasan hutan di luar sektor kehutanan melalui pinjam pakai kawasan hutan dan pemanenan hasil hutan yang tidak memperhatikan prinsip-prinsip pengelolaan hutan lestari. Degradasi atau penurunan kualitas hutan di Indonesia antara lain disebabkan oleh kebakaran dan 
perambahan hutan; illegal loging dan perdagangan ilegal yang antara lain didorong oleh adanya permintaan yang tinggi terhadap kayu dan hasil hutan lainya.

PT. Muara Sungai Landak merupakan perusahaan pemanfaatan hasil hutan kayu yang telah memiliki ijin dari pemerintah dengan areal hutan produksi seluas \pm 13.000 Ha. Peran peruasahaan dalam melindungi kelestarian lingkungan hidup adalah dengan menyediakan kawasan hutan lindung seluas $209 \mathrm{Ha}$ dari total luas area yang dimilikinya. Kawasan ini sebagai penyumbang untuk mengurangi emisi dan mengikat $\mathrm{CO}_{2}$. Di perusahaan belum ada data stok karbon sehingga belum dapat diketahui dengan pasti jumlah karbon yang dapat diserap. Oleh karena itu penelitian tentang stok karbon di kawasan tersebut sangat penting untuk dilakukan.

\section{METODE PENELITIAN}

\section{Objek Penelitian}

Objek dalam penelitian ini adalah pohon (pancang dengan diameter 5-10 $\mathrm{cm}$, tiang dengan diameter $10-20 \mathrm{~cm}$ dan pohon dengan diameter $>20 \mathrm{~cm}$ ), nekromasa dan serasah yang berada di atas permukaan tanah yang ada di dalam plot pengamatan pada kawasan lindung PT Muara Sungai Landak. Lokasi PT Muara Sungai Landak tepatnya pada $109^{0} 14^{\prime} 35^{\prime}-109^{0} 21^{\prime} 50^{\prime \prime}$ BT $00^{0}-15^{\prime}$ $00-00^{0} \quad 14$ ' 35" LU Kecamatan Sugedong dan Siantan, Kabupaten Mempawah, Provinsi Kalimantan Barat.

\section{Pelaksanaan Penelitian}

Metode dalam penelitian ini menggunakan Non-Destructiv sampling atau tanpa penebangan. Metode ini antara lain dilakukan dengan mengukur diameter pohon dan menggunakan persamaan allometric yang sesuai untuk mengestimasi biomassa. Pembuatan petak contoh pada penelitian ini dibagi berdasarkan tutupan lahan (Stratified Sampling) dan sistematik sampling yaitu jarak antar plot yang konsisten.

Petak contoh dengan sistematik sampling yang diletakan berdasarkan tutupan lahan yang tertera pada gambar 1.

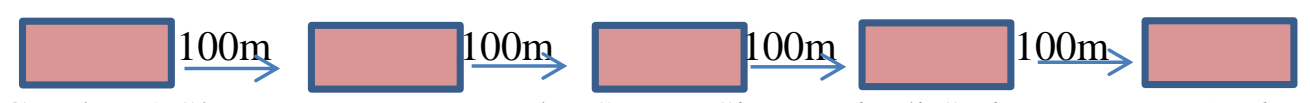

Gambar 1.Skema Penempatan Plot Secara Sistematis di Setiap Tutupan (Schematically Placement Plots on Every Cover).

Bentuk petak contoh untuk ukuran $20 \mathrm{~m}$ x $50 \mathrm{~m}$ disajikan pada pengambilan data biomassa dengan Gambar 2. 


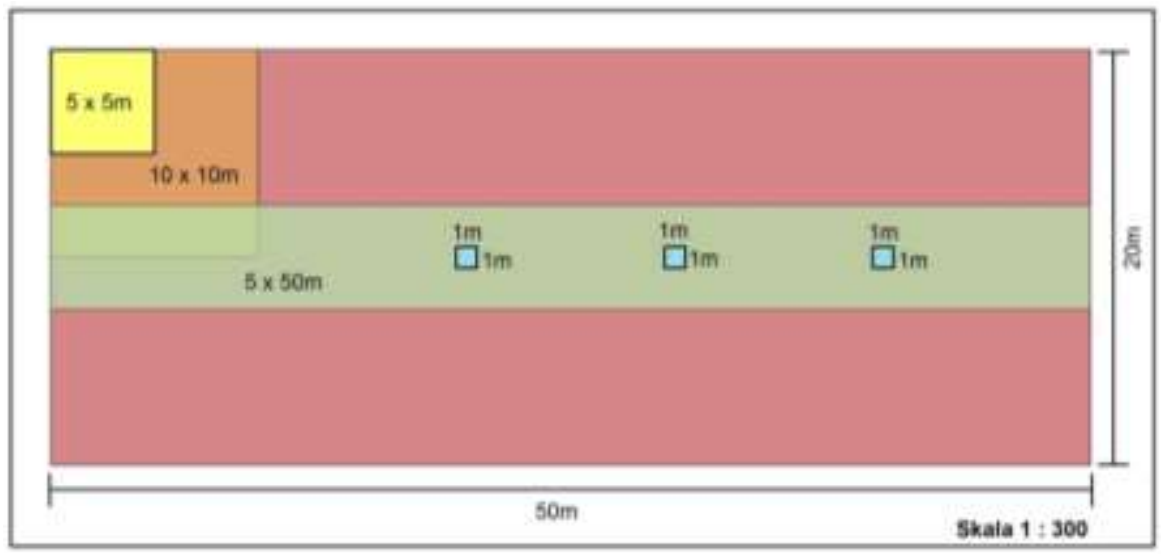

Gambar 2. Metode dalam Pengambilan Data Serasah Tumbuhan Bawah, Pohon Mati dan Vegetasi (Methods for Collecting Data on Lower Plant Litter, Dead Trees and Vegetation)

\section{Data Primer}

Data primer adalah data yang didapat saat pengukuran langsung di lapangan yaitu Hutan alam PT Muara Sungai Landak. Pengukuran langsung di lapangan dilakukan untuk mengambil data vegetasi dan data biomasa. Data primer yang dikumpulkan pada penelitian ini berupa data berikut:

a. Jenis pohon, tinggi total pohon dan diameter pohon pada semua fase ( pancang, tiang dan pohon) untuk pengukuran biomasa.

b. Necromasa

c. Serasah

d. Tumbuhan bawah

Perhitungan biomassa untuk tingkat pancang, tiang dan pohon

Data-data hasil penelitian ini berupa diameter pohon selanjutnya dianalisa dengan menggunaakan persamaan allometric sabagai barikut:

(AGB) est $=p^{*} \exp (-1.499+2.148$

$\left.\operatorname{Ln}(D)+0.207(\operatorname{Ln}(D))^{2}-0.0281(\operatorname{Ln}(D))^{3}\right)$

Katerangan :
$(\mathrm{AGB})$ est $=$ Biomassa pohon bagian atas tanah, $\mathrm{kg} /$ pohon

$\mathrm{D}=$ Diameter Pohon $(\mathrm{cm})$

$\boldsymbol{p}=$ Berat Jenis BJ Kayu, $\mathrm{g} / \mathrm{cm}^{3}$

Sumber: Chave, 2005

Perhitungan biomassa untuk tingkat necromassa

Pengukuran Diameter

Lbds Rata-rata $=\frac{L b d s \emptyset u+L b d s \emptyset p}{2}$

Lbds $\emptyset_{\mathrm{u}=1 / 4} \cdot \pi . \emptyset_{\mathrm{u}^{2}}$

Lbds $\emptyset_{\mathrm{p}=1 / 4} . \pi . \emptyset_{\mathrm{p}^{2}}$

Keterangan :

$\emptyset_{\mathrm{u}}=$ diameter ujung

$\emptyset_{\mathrm{p}}=$ diameter pangkal

$\mathrm{p}=$ panjang

Lbds CWD $=1 / 2\left(\operatorname{Lbds} \emptyset_{\mathbf{u}}+\operatorname{Lbds} \emptyset_{\mathbf{u}}\right) \mathbf{x}(\mathbf{p})$

Volume $\left(\mathrm{cm}^{3}\right)=\pi \mathbf{R}^{2} \mathbf{T}$

Keterangan :

$\mathrm{R}=$ jari-jari potongan kayu $=1 / 2 \mathrm{X}$

diameter $(\mathrm{cm})$

$\mathrm{T}=$ Panjang Kayu $(\mathrm{cm})$

Sumber: (Rahayu, S et al. 2007) 
Untuk jenis vegetasi yang belum mempunyai betrat jenis maka akan di hitung menggunakan hukum archimedes dan dilakukan pengukuran di laboratorium.

\section{Perhitungan Biomassa}

Untuk menghitung biomassa pohon mati yang sudah rebah ( Coarse Woody Debris ) CDW

Biomassa $(\mathrm{Kg})=$ Berat Jenis $\left(\mathrm{gr} / \mathrm{cm}^{3}\right)$ $\mathrm{x}$ Volume $\left(\mathrm{cm}^{3}\right)$

Untuk menghitung biomassa pohon mati yang masih tegak (Standing Woody

Debris ) SWD :

$\mathrm{W}=\mathbf{0 , 0 4 9} \cdot \mathbf{p} \cdot \mathbf{D}^{\mathbf{2}} \cdot \mathbf{h}$

Keterangan :

$\mathrm{W}=$ Biomassa

$\mathrm{P}=$ Berat jenis

$\mathrm{h}=$ tinggi

$\mathrm{D}=$ diameter

Sumber: Brown 1997

Perhitungan biomassa untuk serasah

Penghitungan karbon dari bahan organik mati dari serasah, kayu mati dan pohon mati menggunakan rumus sebagai berikut:

Bo $=\frac{B k s x B b t}{B b s}$

Keterangan:

Bo = berat bahan organik, dinyatakan dalam kilogram $(\mathrm{kg})$

Bks = berat kering contoh, dinyatakan dalam kilogram $(\mathrm{kg})$

$\mathrm{Bbt}=$ berat basah total, dinyatakan

dalam kilogram $(\mathrm{kg})$

$\mathrm{Bbs}=$ berat basah contoh, dinyatakan

dalam (kg).

$\mathrm{Cm}=\mathrm{Bo} \times$ \% $\mathrm{C}$ organik

Keterangan:
$\mathrm{Cm}=$ kandungan karbon bahan organik mati, dinyatakan dalam kilogram

Bo = total biomassa/bahan organik, dinyatakan dalam kilogram $(\mathrm{kg})$;

$\% \mathrm{C}$ organik $=$ nilai persentase kandungan karbon, sebesar 0,47 atau menggunakan nilai persen karbon yang diperoleh dari hasil pengukuran di laboratorium

Sumber:SNI-7724-2011pengukuran dan perhitungan cadangan karbon

1. Biomasa Pohon

Biomasa pohon diukur dengan metode nondestructive untuk fase pancang, tiang serta pohon, dan destructive untuk fase semai. Data biomasa yang diolah dibedakan antara biomasa fase pohon, fase tiang, dan pada fase pancang karena luasan plot yang berbeda pada masing-masing fase. Berdasarkan data jenis, diameter dan tinggi, selanjutnya data biomasa dapat diperoleh menggunakan persamaan allometrik yang telah ada.

2. Nekromasa

Karbon nekromasa diukur pada pohon mati yang masih berdiri tegak maupun roboh, juga kayu mati dengan metode SNI (BSN, 2011). Berdasarkan data jenis pohon, diameter, tinggi/panjang, serta tingkat keutuhan pohon dilakukan penghitungan biomasa menggunakan persamaan allometrik sesuai dengan jenis pohonnya. Biomasa pohon mati diperoleh dari hasil kali biomasa pohon tersebut dikalikan dengan faktor koreksinya. Faktor koreksi ditentukan berdasarkan tingkat keutuhan pohon mati dengan klasifikasi sebagai berikut: 


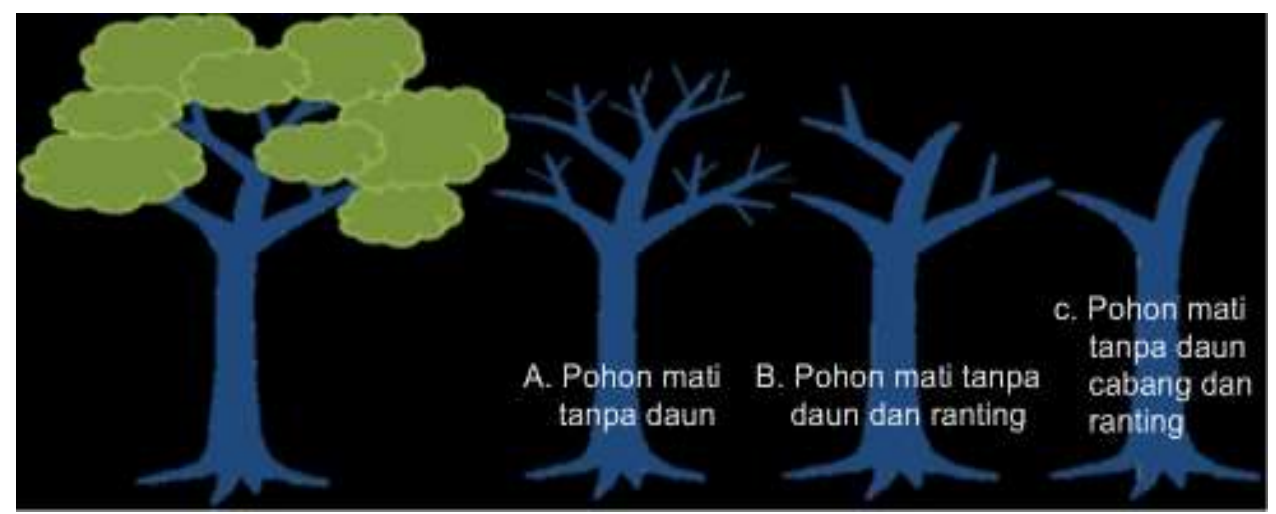

Sumber : SNI 7724:2011

Gambar 3. Klasifikasi Tingkat Keutuhan Pohon (Classification the Integrity of Trees) Keterangan:

a. Pohon mati tanpa daun dengan faktor koreksi 0,9 .

b. Pohon mati tanpa daun dan ranting dengan faktor koreksi 0,8 .

c. Pohon mati tanpa daun, ranting dan cabang dengan faktor koreksi 0,7 .

HASIL DAN PEMBAHASAN

1. Potensi Biomassa dan Karbon

\section{Tegakan}

Tegakan pada area penelitian ini pada tingkatan pancang, tiang dan pohon Biomassa ini dihitung dari

Tabel 1. Estimasi Biomassa dan Karbon pada Tegakan berdasarkan Tutupan Lahan (Estimation of Biomass and Carbon in Stands based on Land Cover)

\begin{tabular}{lccccc}
$\begin{array}{c}\text { Tabel 1. Estimasi Biomassa dan Karbon pada Tegakan berdasarkan Tutupan } \\
\text { Lahan } \\
\text { Cover) }\end{array}$ & & & & & \\
& (Estimation & of Biomass & and Carbon in Stands based on Land \\
Tutupan Lahan & Pancang & Tiang & Pohon & Total Biomassa & Total Karbon \\
Ton/Ha & Ton/Ha & Ton/Ha & Ton/Ha & Ton/Ha \\
\hline Belukar Muda & 8,56 & 39,79 & 63,73 & 238,47 & 112,08 \\
Belukar Tua & 12,99 & 28,8 & 87,06 & 274,165 & 128,85 \\
Lahan Gambut & 6,89 & 10 & 5,82 & 48,35 & 22,71 \\
Terbuka & & & & & \\
\hline
\end{tabular}

Data tersebut menunjukan bahwa tegakan pada tutupan lahan belukar tua lebih besar menyimpan karbon, dikarenakan pada tutupan lahan belukar tua masih banyak ditemukan tingkat pohon dan tiang. Semakin besar diameter pohon semakin banyak karbon yang terserap oleh tumbuhan melalui keseluruhan pada masing-masing plot penelitian. Jumlah plot pengamatan adalah 13 (tiga belas) buah plot dengan ukuran sebesar 20x50 meter. Adapun hasil rekapitulasinya dapat dilihat pada tabel 1. proses fotosintesis. Oleh karena itu jika pohon ditebang maka fungsi sebagai penyerap karbon (sequestrasi) akan berkurang signifikan dan karbon yang tersimpan akan terlepas dan teremisi di udara. 


\section{Biomassa Nekromas dan karbon}

\section{(CoarsWoody Debris, Standing}

Woody Debris)

Pengukuran biomassa kayu mati tegak dilakukan pengukuran diameter dan tinggi kayu, sedangkan untuk pengukuran kayu mati rebah dilakukan pengukuran diameter pangkal dan diameter ujung serta panjang kayu mati kemudian diambil sampel tersebut untuk diukur masing-masing volume kayu. Estimasi Biomassa dan Karbon pada nekromas berdasarkan tutupan lahan disajikan pada tabel 2.

Tabel 2. Estimasi Biomassa dan Karbon pada Nekromas berdasarkan Tutupan Lahan (Estimation of Biomass and Carbon in Nekromas based on Land Cover)

\section{Tutupan Lahan}

Total Biomassa (Ton/Ha )
Total Karbon (Ton/Ha)

\begin{tabular}{lcc}
\hline Belukar Muda & 3,96 & 1,86 \\
Belukar Tua & 11,72 & 5,51 \\
Lahan Gambut Terbuka & 1,60 & 0,75 \\
\hline
\end{tabular}

Pada kelas nekromas data menunjukan simpanan karbon terbesar berada pada tutupan lahan Belukar tua, karena pada tutupan ini lebih banyak ditemukan pohon mati rebah maupun berdiri dibandingkan dengan Belukar muda maupun Lahan gambut terbuka.

\section{Biomassa dan Karbon pada}

Serasah
Pengukuran Biomassa dan Karbon pada serasah dilakukan pada sub plot $1 \mathrm{~m} \times 1 \mathrm{~m}$ sebanyak 3 sub plot dengan jarak $15 \mathrm{~m}$ antar sub plot. Kemudian diambil sample untuk dibawa ke laboratorim untuk di analisis. Estimasi Biomassa dan Karbon pada serasah berdasarkan tutupan lahan disajikan pada tabel 3.

Tabel 3. Estimasi Biomassa dan Karbon pada Serasah berdasarkan Tutupan Lahan (Estimation of Biomass and Carbon in Litter based on Land Cover)

\begin{tabular}{|c|c|c|}
\hline Tutupan Lahan & $\begin{array}{c}\text { Total Biomassa } \\
\text { (Ton/Ha) }\end{array}$ & $\begin{array}{c}\text { Total Karbon } \\
\text { (Ton/Ha) }\end{array}$ \\
\hline Belukar Muda & 2,84 & 1,33 \\
\hline Belukar Tua & 4,78 & 2,24 \\
\hline Lahan Gambut Terbuka & 3,23 & 1,54 \\
\hline $\begin{array}{l}\text { Serasah mempunyai peranan } \\
\text { penting dalam keberlangsungan siklus } \\
\text { hara di dalam ekosistem hutan dan } \\
\text { berhubungan erat dengan struktur hutan } \\
\text { (Rahayu, dkk.,2007). Berdasarkan hasil } \\
\text { estimasi diatas menunjukan } \\
\text { bahwasannya siklus hara pada belukar } \\
\text { tua lebih bagus dari tutpan lainnya. }\end{array}$ & $\begin{array}{r}\text { 4. Bi } \\
\mathbf{T t} \\
\text { F } \\
\text { pada } \\
\text { seper } \\
\text { Biom } \\
\text { bawa } \\
\text { disaji }\end{array}$ & $\begin{array}{l}\text { Karbon pada } \\
\text { awah } \\
\text { Biomassa dan Karbon } \\
\text { awah dilakukan sama } \\
\text { ran serasah. Estimasi } \\
\text { arbon pada tumbuhan } \\
\text { kan tutupan lahan } \\
\text { el } 4 \text {. }\end{array}$ \\
\hline
\end{tabular}


Vol. 7 (1) : 551 - 558

Tabel 4. Estimasi Biomassa dan Karbon pada Tumbuhan Bawah berdasarkan Tutupan Lahan ( Estimation of Biomass and Carbon in Lower Plants based on Land Cover)

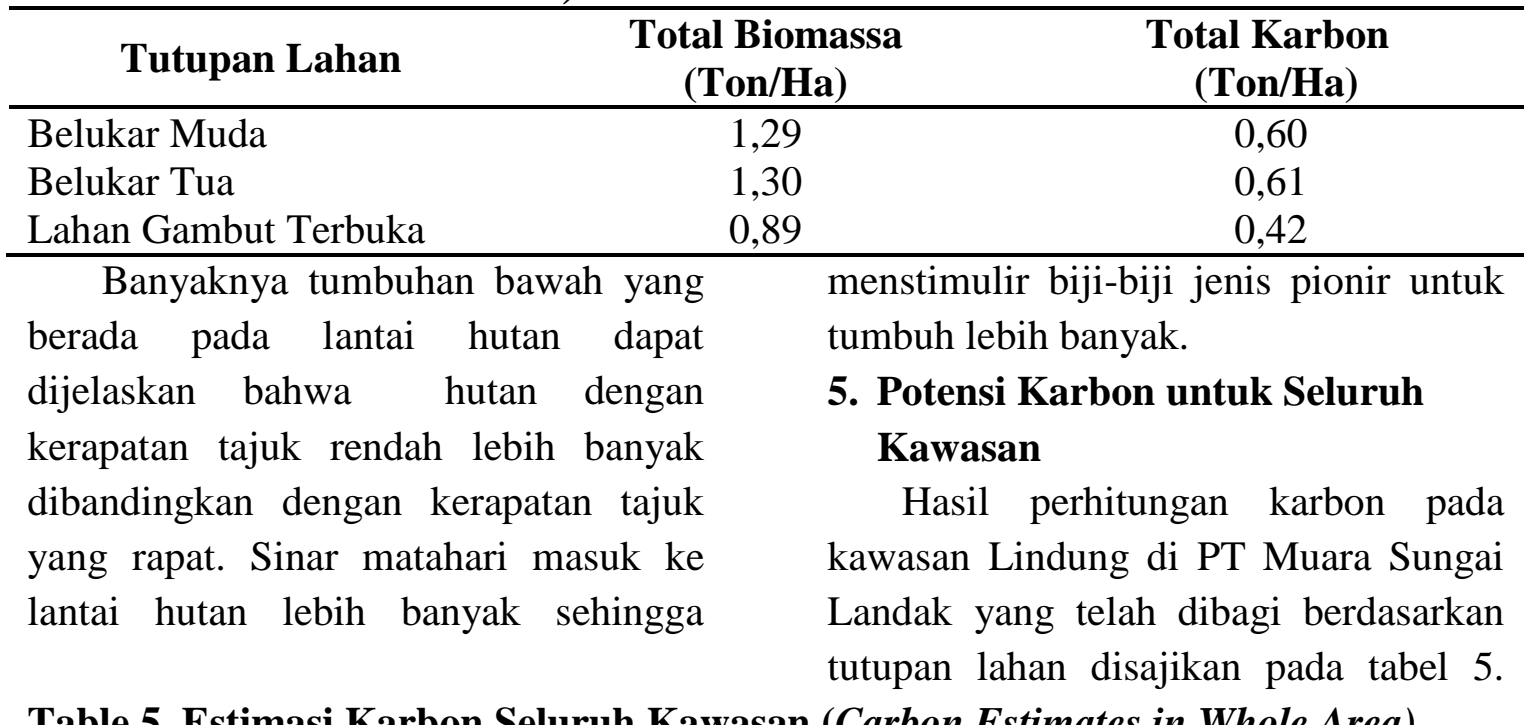

Table 5. Estimasi Karbon Seluruh Kawasan (Carbon Estimates in Whole Area)

\begin{tabular}{|c|c|c|c|c|c|c|}
\hline $\begin{array}{c}\text { Tutupan } \\
\text { Lahan }\end{array}$ & $\begin{array}{l}\text { Luas } \\
\text { (Ha) }\end{array}$ & $\begin{array}{c}\text { Tegakan } \\
(\text { Ton/Ha) }\end{array}$ & $\begin{array}{c}\text { Nekromas } \\
\text { (Ton/Ha) }\end{array}$ & $\begin{array}{c}\text { Serasah } \\
\text { (Ton/Ha) }\end{array}$ & $\begin{array}{c}\text { Tumbuhan } \\
\text { Bawah } \\
\text { (Ton/Ha) } \\
\end{array}$ & \\
\hline $\begin{array}{l}\text { Belukar } \\
\text { Muda }\end{array}$ & 89,38 & 112,08 & 1,86 & 1,33 & 0,60 & $10.356,46$ \\
\hline $\begin{array}{l}\text { Belukar Tua } \\
\text { Lahan }\end{array}$ & 112,42 & 128,85 & 5,51 & 4,78 & 0,61 & $15.425,15$ \\
\hline $\begin{array}{l}\text { Gambut } \\
\text { Terbuka }\end{array}$ & 7,42 & 22,71 & 0,75 & 3,23 & 0,42 & 188,46 \\
\hline
\end{tabular}

\begin{tabular}{|c|c|}
\hline \multicolumn{2}{|c|}{ Total karbon di seluruh kawasan } \\
\hline Berdasarkan & Nilai karbon tersimpan menyatakan \\
\hline vegetasi pada penelitian ini bahwasannya & banyaknya karbon yang mampu diserap \\
\hline pada tutupan belukar tua sebesar 128,8 & oleh tumbuhan dalam bentuk biomassa. \\
\hline ton/ha. Hasil ini sebanding dengan & Jumlah karbon yang semakin meningkat \\
\hline penelitian Astiani (2014) pada hutan rawa & pada saat ini harus diimbangi dengan \\
\hline gambut sekunder kuala dua di Kalimantan & jumlah serapannya oleh tumbuhan guna \\
\hline Barat yaitu sebesar 128,4 ton/ha dan lebih & mengurangi pemanasan global. Dengan \\
\hline besar dari penelitian Jauhianien (2005) & demikian dapat diramalkan berapa $\mathrm{b}$ \\
\hline pada hutan terdegradasi berat di & tumbuhan yang harus di tanam pada suatu \\
\hline $\begin{array}{l}\text { Kalimantan Tengah yaitu sebesar } 31,4 \\
\text { ton/ha dan FREL (2016) pada hutan rawa }\end{array}$ & $\begin{array}{l}\text { lahan untuk mengimbangi jumlah karbon } \\
\text { yang terbebas di udara (Ariani, 2014). }\end{array}$ \\
\hline (5) & \\
\hline
\end{tabular}

\section{KESIMPULAN}

Berdasarkan hasil penelitian potensi karbon yang terkandung pada Area 
Kawasan lindung PT. Muara Sungai Landak adalah 25.970,08 ton C. Dengan karbon tertinggi pada tutupan lahan Belukar tua yaitu dengan total 15.425,15 ton C, kemudian Belukar muda 10.356,46 ton/ha dan terkecil adalah Lahan gambut terbuka sebesar 188,46 ton C.

\section{SARAN}

a Disarankan untuk dapat dilakukannya penelitian lebih lanjut mengenai kandungan karbon di dalam tanah untuk melengkapi data base perusahaan.

b Adanya data potensi karbon tersimpan ini diharapkan menjadi acuan dasar yang berkelanjutan dalam hal pengelolaan Kawasan lindung PT. Muara Sungai Landak untuk lebih ditingkatkan lagi kelestariannya sebagai salah satu kawasan penyimpan karbon (carbon stock).

\section{DAFTAR PUSTAKA}

Ariani. Sudartono A, Wahid A. 2014. Biomassa dan karbon Tumbuhan bawah sekitar Danau Tambing pada Kawasan Taman Nasional Lore Lindu. Fakultas Kehutanan Universitas Tadulaku

Astiani D. 2014. Bornean Peatlands: Forest Dynamics, Land Use and Carbon Flux. Doctoral Dissertation. Disertasi. Graduate School of Yale University. USA.

Badan Standardisasi Nasional (BSN). 2011. Pengukuran dan Penghitungan Cadangan Karbon. Pengukuran Lapangan untuk Penaksiran Cadangan Karbon Hutan
(Ground Based Forest Carbon Accounting). Buku. Badan Standardisasi Nasional. Jakarta.

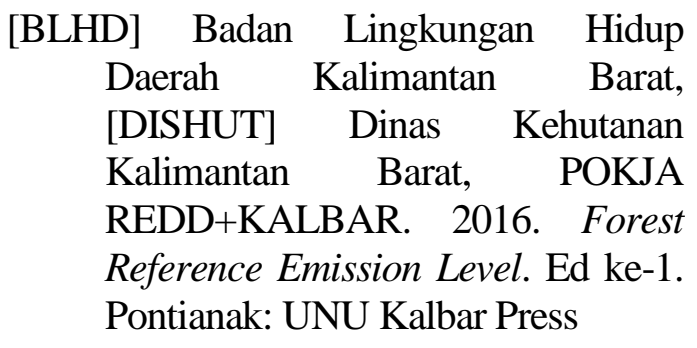

Brown, S. 1997. Estimating Biomass and Biomass Change of Tropical Forests: A Primer UN FAO. Forestry Paper 134, pp 55. Diakses 1 April 2014 dari http://www.fao.org/docrep/W4095E /W4095E00.htm

Hairiah K, dan Rahayu S. 2007. Pengukuran Karbon Tersimpan di Berbagai Penggunaan Lahan. Buku. World Agroforestry Center-ICRAF. Bogor. 77p.

Jauhiainen J, Takashi H, Heikkinen EP, Martikainen PJ and Vasander $\mathrm{H}$. 2005. Carbon Fluxes From a Tropical Peat Swamp Forest Floore. Global Change Biology. 1788-1797

Lukito M, dan Rohmatiah A. 2013. Estimasi biomassa dan karbon tanaman jati umur 5 tahun (kasus kawasan hutan tanaman Jati Unggul Nusantara (JUN) Desa Krowe, Kecamatan Lembeyan Kabupaten Magetan). Agri-tek. 14 (1): 1-23.

Rahayu S, Lusiana B, Noordwijk M. 2007. Pendugaan cadangan karbon di atas permukaan tanah pada berbagai sistem penggunaan lahan di Kabupaten Nunukan, Kalimantan Timur. 14 hal. 